\title{
Day Times Picogram per Milliliter per Meter Squared
}

National Cancer Institute

\section{Source}

National Cancer Institute. Day Times Picogram per Milliliter per Meter Squared. NCI

Thesaurus. Code C111186.

Days times picograms per milliliter, divided by meters squared. 